\title{
The effect of leucotomy in intractable adolescent weight phobia (primary anorexia nervosa)
}

\author{
A. H. CRISP \\ R. S. KaLUCY \\ M.D., F.R.C.P.(E)., M.R.C.P., F.R.C.Psych., D.P.M. M.B., M.R.A.C.P., M.A.N.Z.C.P., M.R.C.Psych.
}

St George's Hospital Medical School, Tooting, London, S.W.17

\begin{abstract}
Summary
Anorexia nervosa is best construed as a phobic avoidance response to the psychosocial maturational implications of adolescent weight. Within this state, surrender to the impulse to eat and consequent weight gain is associated with panic, depression and sometimes specific intense fear of loss of control. So long as the avoidance posture can be maintained the experience of such turmoil is largely avoided.

Complicated ritualistic behaviour may arise to promote and secure the posture. However, its unrewarding and lonely nature still increasingly leaves the individual liable to the experience of depression. Established treatment procedures often assist recovery from the illness but intractable cases arise and it is amongst these that the majority of deaths occur either from inanition or suicide.

The basis for the changes characteristically induced by leucotomy is complex. The procedure often leads to reduced tension and release of appetitive behaviour. This is taken to be due to some direct effect of the cerebral lesion and possibly the intervention may also be construed by some patients as a licence to behave differently. In patients with anorexia nervosa such appetitive release can be expected to promote considerable weight gain. However, the adverse psychological implications of such weight gain for the patient do not appear always to be so immediately or easily relieved.

They may still experience panic, shame or depression and new patterns of social avoidance, or vomiting behaviour may develop. Intensive help of a psychotherapeutic and rehabilitative kind is then still required if the patient is to have the best chance of adjusting healthily to her newly found potential for a more normal nutritional status. Four patients who have undergone such treatment are described in this paper. It is concluded that leucotomy has a small but definite place in the treatment of patients with intractable anorexia nervosa.
\end{abstract}

\section{Introduction}

The disorder of primary anorexia nervosa is now well defined. In particular, it has to be distinguished from secondary anorexia nervosa within the realm of psychiatric illnesses, and from a variety of primarily physically based disorders. It usually develops in adolescent females, almost invariably within the context of dieting behaviour (carbohydrate avoidance), and is usually evidently characterized by an inability to eat, especially carbohydrate foods, attendant emaciation, amorrhoea, hyperactivity and hypometabolism. The patient is usually preoccupied with thoughts of food and with ways of avoiding and otherwise controlling its ingestion. Very complex feeding patterns arise in about $20 \%$ of cases. Many of the latter symptoms and related behaviour may be concealed and their existence denied. In particular, the central psychopathological core of the illness, an intense fear of weight gain especially to adult proportions (a phobia of normal adolescent weight), is often denied. The patient perceives the state of normal weight as a state of fatness, especially if she has been overweight pre-morbidly. It has been proposed that the disorder arises as a phobic avoidance response to the maturational demands of puberty and adolescence (Crisp, 1967a). Patients need to maintain their weight at or below the suppubertal threshold. A fear of loss of control of eating, hence weight, and thereafter of themselves and their situation, is often present.

The course of the disorder is highly variable. Death can occur, usually through inanition or suicide, and most commonly in those patients who are chronically ill and who have chronic feeding patterns of overeating and vomiting, and who ingest excessive quantities of purgatives as a further means of weight control.

Treatment is difficult. Most authorities agree that restoration of weight is an important first step. In this unit, the patient's weight is restored to matched population mean levels as one aspect of an intensive treatment programme, including psychotherapy with the patient and other family members. This approach leads immediately to approximately half of such patients remaining recovered from their primary anorexia nervosa (Crisp, 1970). Other relapse to some extent. A number still eventually recover with 
further out-patient care. A minority relapse completely and may become acutely ill once more. In this case they are usually re-admitted and treated once again in the same way.

Leucotomy has only rarely been undertaken as a treatment in patients with anorexia nervosa. It is usually a treatment of last resort. Particular difficulties arise since the patient, even when in a terminal state, may insist that she is well and that she does not need treatment. Clearly, intervention by any treatment such as leucotomy is only justified if the patient fully understands the nature of the advised treatment and clearly wishes to undertake it after learning all there is to know concerning the range of possible outcomes.

The reports of outcome in the literature reveal that of about ten cases, some have done well postoperatively in the sense that they have survived and gained weight, although not always in a stable way (Altschule, 1953; Carmody \& Vibbler, 1952; Dally, 1969; Drury, 1950; Glazebrook, Matas \& Prosen, 1956; Hemphill, 1944; Kelly \& Mitchell-Heggs, 1973; Mallinson, 1953; Sargant, 1951; Sifneos, 1952). Feeding patterns have not always stabilized. For instance, some patients developed uncontrollable overeating and related vomiting patterns. One potentially disastrous effect of leucotomy in this condition has been described (Crisp, 1967b), whereby it may strip the patient of her capacity to resist eating whilst in no way affecting her sense of terror, guilt or shame at her consequent weight gain. Such effects call into question the mechanism whereby leucotomy alters the course of primary anorexia nervosa. Whereas the principal indication for leucotomy in adult psychiatric patients is an aversive state of chronic and relentless tension or depression together with certain stable personality characteristics, these features are not present in the same way in patients with anorexia nervosa. Brain damage of various kinds can have the effect of releasing appetitive behaviour and such patients sometimes show increased activity of a sexual kind and perhaps more often of a feeding kind. They may become inactive and obese. Such effects not infrequently occurred with the early and rather crude leucotomy procedures. In the past, this effect of weight gain may have provided some seemingly rational basis for the recommendation of leucotomy to occasional patients with anorexia nervosa in whom all other treatments had failed.

\section{Present study}

Over the last 12 years the first author has gathered a series of 250 patients with primary anorexia nervosa. The majority of these have received inpatient care for one, and occasionally more than one, period of about 4 months. Most of these patients are now well. Of the remainder a total of five who were amongst those in whom such recurrent treatment methods had failed, and whose prognosis was otherwise unquestionably poor, have so far eventually been advised to undergo leucotomy. One has refused and at this present time remains in a state of seemingly terminal illness, bedridden, weighing about $28 \mathrm{~kg}$ and with severely deranged metabolic status(e.g. serum Karound $1 \mathrm{~m} /$ lit, related to incessant and secretive purging), generating amongst other things occasional epilepsy. She has been ill like this for 6 years apart from 2 periods in hospital when her weight, her general physical well-being, and to some extent her psychological health, had been briefly restored to normal levels. However, despite our grave prognostications, she is still surviving. This report now concerns the four patients who decided to accept treatment by leucotomy (Fig. 1).

Subject No. 51

A 36-year-old married woman referred with a diagnosis of chronic anorexia nervosa of 20 years' duration, punctuated by 3 transitory episodes of 'recovery' during each of which she had become pregnant and produced a live child before once again immediately relapsing. The patient's father, a senior officer in the services, had probably also had chronic anorexia nervosa and had also been a heavy drinker. The mother, previously very slim, had become obese since her husband's death. The patient had led a lonely, insecure childhood, brought up by nannies and, when her parents separated when she was aged 16 , she continued to live with her father, becoming the hostess in his home. At the same time she plunged into a series of unsatisfactory relationships with boyfriends. A skinny child, she had become plump in adolescence and determined to diet aged 16 after someone had commented on her pregnant appearance. She rapidly lost weight from $58 \mathrm{~kg}$ down to 41 kg (amenorrhoea supervening early on), and entered a state of severe anorexia nervosa with features of bulimia and vomiting and secretive purging. In accord with this variant of the disorder she typically embarked upon work in a menial capacity in bakeries and hotels. At the same time the pattern of her disastrous sexual adventures with a series of psychopathic males intensified.

Next she abruptly married a rather obsessional and rigid man by whom she had the three children referred to above. When she was aged 23 her father died and thereafter she became more ill, drinking heavily, overeating and vomiting almost continually, and with her weight usually below the $35 \mathrm{~kg}$ mark. On several occasions she was investigated fruitlessly for unexplained vomiting, diarrhoea, etc. On other occasions attempts were made to treat her concurrent depression and/or the anorexia nervosa itself. At the time of her present admission she weighed 23.5 

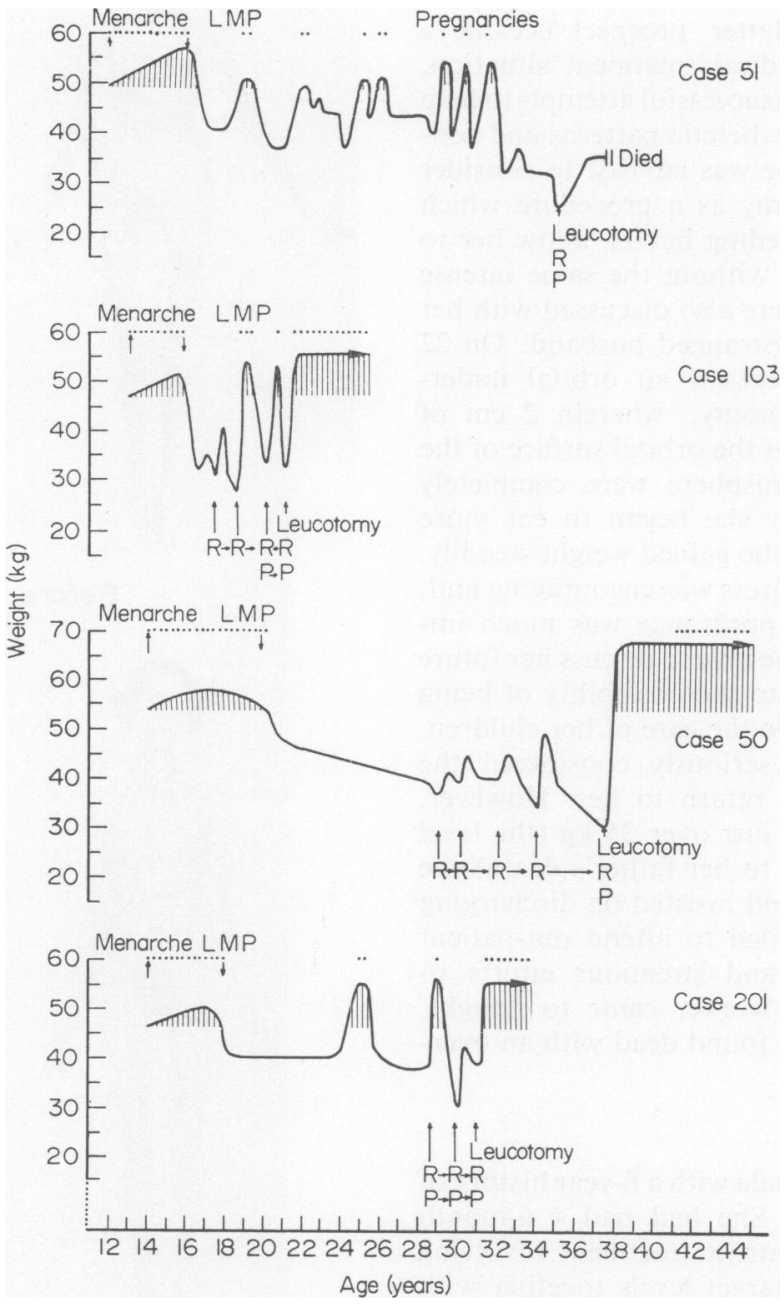

Fig. 1. The course of the illness, expressed in terms of body weight, of four patients who eventually underwent leucotomy. The shaded areas are intended to give a rough indication of weights at which the patients can be expected to have experienced the effects of biological maturity. The chart also indicates patterns of frank menstrual activity and the varieties of previous treatments. $\mathbf{R}$, refeeding; $\mathbf{P}$, psychotherapy. 
$\mathrm{kg}$, was cadaverous-looking and showed the typical paradoxical metabolic responses (e.g. racing pulse, sweating) indicative of concurrent (secret) overeating and vomiting. Her initial professed desire to gain weight and apparent mystification at being unable to do so gave way to her evident and basic terror of weight gain once this latter prospect became a possibility within the medical treatment situation. After various essentially unsuccessful attempts to help her through control of her dietetic patterns and concurrent psychotherapy, she was advised to consider the possibility of leucotomy as a procedure which might both modify her feeding habits, allow her to gain weight and to do so without the same intense fear. These possibilities were also discussed with her mother and her by now estranged husband. On 22 December 1964 she underwent an orbital undercutting pre-frontal leucotomy, wherein $2 \mathrm{~cm}$ of cortex in the medial part of the orbital surface of the frontal lobe of each hemisphere were completely undercut. Post-operatively she began to eat more normally and vomit less. She gained weight steadily. For several weeks her progress was encouraging and, of course, her physical appearance was much improved (Fig. 2). She became able to discuss her future and was looking forward to the possibility of being allowed to once again have the care of her children. Her husband now also seriously considered the possibility that he might return to her. However, when her weight reached just over $35 \mathrm{~kg}$ (the level she had maintained prior to her father's death) she became acutely agitated and insisted on discharging herself from care. She failed to attend out-patient follow-up appointments and strenuous efforts to locate her by the social worker came to nought. Three weeks later she was found dead with an overdose of hypnotics.

\section{Subject No. 103}

A 22-year-old single female with a 6-year history of severe anorexia nervosa. She had had 4 6-month periods of intensive in-patient treatment involving restoration of weight to target levels together with extensive psychotherapy and behaviour therapy, but had relapsed after each occasion, falling quickly to a weight around $35 \mathrm{~kg}$ at which point she required emergency admission in a state close to death.

The youngest of three, she had been a shy, phobic, insecure child in contrast to her more boisterous and plumper sisters. The family background was stable but the parents were strict in their outlook, the father remote and the mother over-protective. The patient had always felt the least favoured and indeed it was explicit in the family that both the parents had hoped for a son as their third child.

As the elder sisters left home the patient first began to eat somewhat more than usual, then

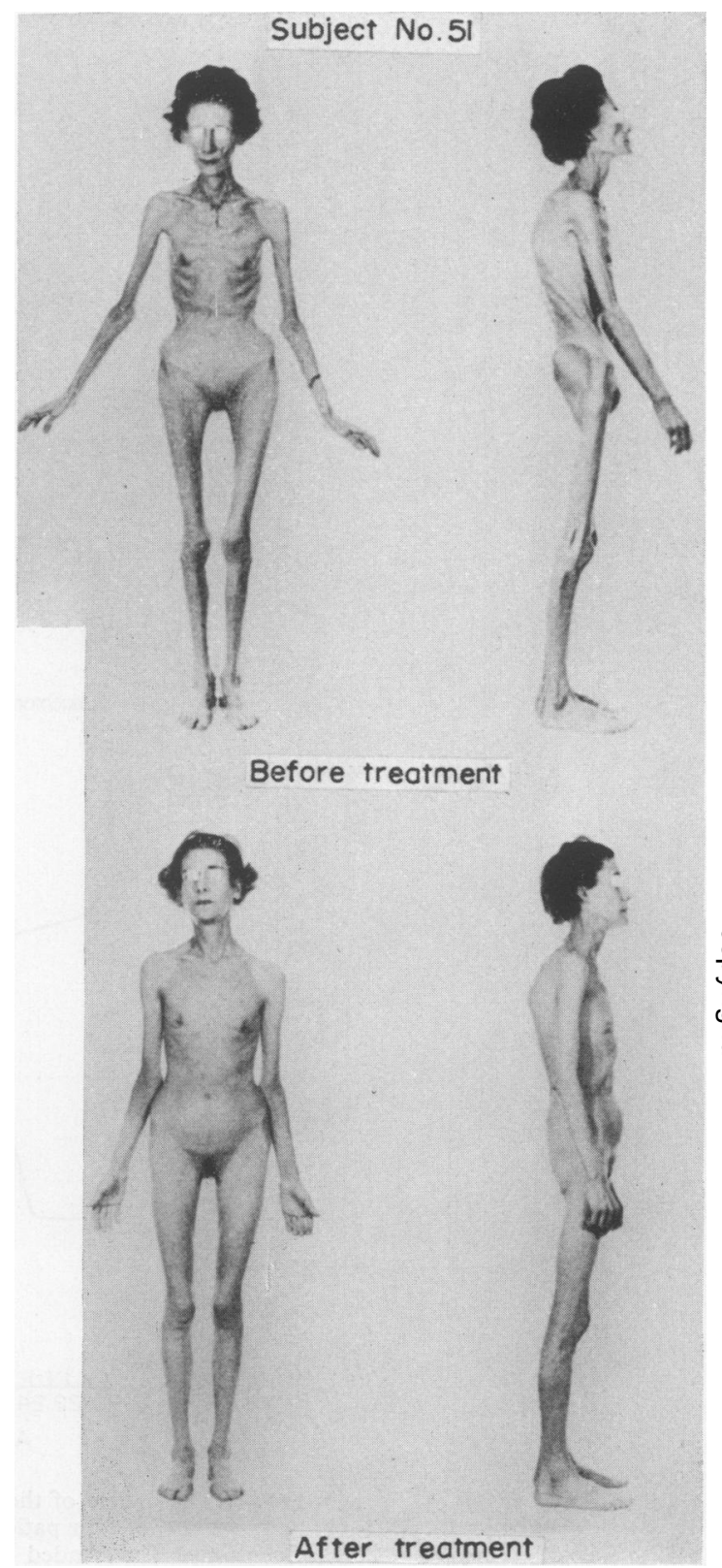

Fig. 2. Patient no. 51. Physical appearance before leucotomy $(23.5 \mathrm{~kg})$ and just prior to the time that she discharged herself about 2 months after leucotomy $(35 \mathrm{~kg})$. Whilst to others her physical appearance was considerably improved, she herself experienced mounting terror of her progressive weight gain.

panicked about her minor weight gain and embarked upon her diet. As anorexia nervosa supervened it seemed likely that her state reflected both her inability to cope with what would otherwise have 
been the emerging demands of her own adolescence, and also the opportunity that was offered at last for her to secure her position as an 'only child' within the now reduced family group.

Her fear and depression at being briefly exposed to her normal weight during the periods of hospital care were apparent to all. Whenever she was admitted to hospital she evoked typical intense caring feelings in the nursing staff, but when such in-patient treatment had failed for the fourth time it was agreed to advise her and her family that she should consider having a leucotomy.

This prospect was discussed with all concerned and they were encouraged to seek advice as widely as possible. The patient and her family eventually decided that she should undergo the operation and on 31 March 1971 a cryogenic stereotactic limbic leucotomy was performed in which four bilateral lesions in the lower medial quadrant of the frontal lobe (1, 2, 3 and 3a; Richardson 1973) were made. Post-operatively sheembarked on the usual treatment programme and as on previous occasions her weight steadily rose. It was not until 6-8 weeks later, as she approached her target weight once more, that staff noticed that she now appeared more relaxed and spontaneous in her manner. Whereas in the past she had been unable to describe or acknowledge any fantasy life, she was now able to record her feelings, wishes and dreams in a fruitful manner.

During this time cyclical $\mathrm{LH}$ and FSH activity recommenced. This aspect of the case is described elsewhere (Crisp et al., 1973). When she reached target weight, she was slowly mobilized and assumed increasing responsibility for her own food intake and levels of activity. Her cyclical menstrual bleeding recurred early on. After a further 3 months in hospital, during which time psychotherapy with her and her family continued, she was discharged home.

She embarked on a nursing training and established herself as a prize-winning student. The next year or so she remained very well, leading an active but somewhat socially restricted life. Subsequently she developed her first relationship with a young man and coped steadily and happily within it. Now, 1 year later, she remains well. Both she and her parents are very pleased indeed that she had the operation.

\section{Subject No. 50}

A 35-year-old single woman admitted in extremis for the second occasion and with a 20 -year history of anorexia nervosa. Brought up as an only child by a strict remote father and fussing insecure mother, she had herself been plump and sensitive throughout childhood. She had gained a reputation for excessive eating especially at parties, apparently thereby gaining the approval of her mother and some recognition from other children. Her mother spoke explicitly and repeatedly to her of the necessary evil of menstruation and sex. Shortly after her menarche she developed a severe obsessional illness with washing and cleaning rituals.

Around the age of 14 years and weighing $60 \mathrm{~kg}$, she embarked upon a diet in order to be able to lose weight and feel more self-confident and free of her mother's influence. An intense weight phobia with early onset amenorrhoea supervened and persisted thereafter, fluctuating in degree. She continued to strive in her academic activities and then qualified SRN before working as a nurse for the next 11 years. During this period she was investigated frequently and variously for her low weight, marked hirsutes, amenorrhoea and her periodic oedema.

The pattern of her related feeding disorder remained predominantly one of abstinence, but with very occasional bulimia and vomiting and chronic secretive purging, whereby she managed to maintain her weight at around the $44.5 \mathrm{~kg}$ mark and no more.

At the age of 30, after venturing to Denmark for a holiday, her weight fell precipitately to $32 \mathrm{~kg}$ and thereafter she remained much more severely ill, unable to work and requiring frequent hospital admissions, the last two of which have been referred to above. On these occasions she would never stay in for longer than was required to resuscitate her from the immediate crisis.

At other times she was occasionally able to indicate her wish for out-patient psychotherapeutic help but was never able to tolerate such intervention for any length of time, terrified that she might surrender to her long-standing impulse to eat and thereby initiate major weight gain.

On the occasion of this latest admission to hospital the possibility of her undergoing leucotomy as a preamble to major rehabilitative endeavour was put to her. The prospect in view, namely the task confronting her of accommodating to her genital sexuality and all its implications after a period of 20 years' illness and avoidance of such issues, was discussed at length with her. She decided to have the operation. On 17 February 1967 she underwent an orbital undercutting pre-frontal leucotomy, wherein $2 \mathrm{~cm}$ of cortex in the medial part of the orbital surface of the frontal lobe of each hemisphere were completely under-cut.

Post-operatively she immediately began to eat larger meals and gained weight in the way shown in Figs. 1 and 3. Up to the point when her weight reached about $51 \mathrm{~kg}$ her eating was fairly normal within the usual formal treatment regime, which involved her staying in bed and having her diet prescribed together with twice weekly psychotherapy. At this point, when it can be assumed that her endocrinological status was undergoing its most rapid changes (e.g. see body temperature record, Fig. 


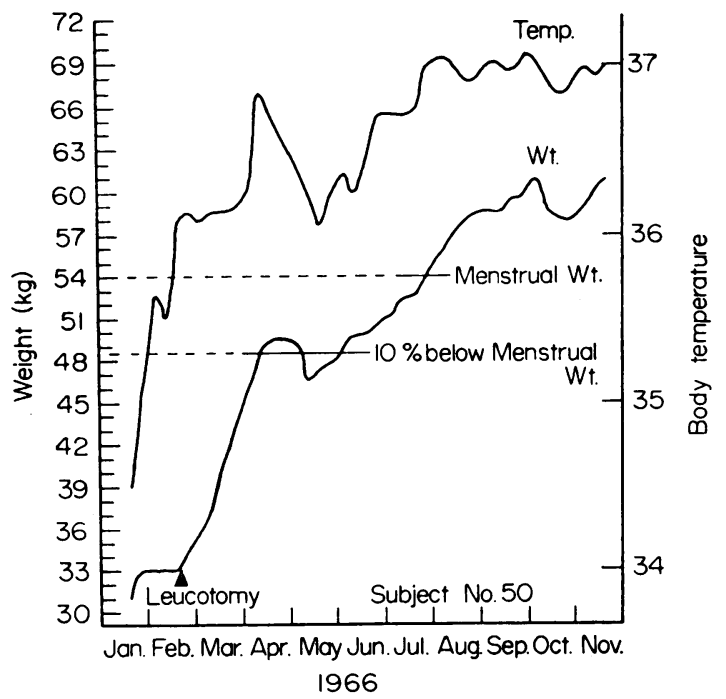

Fig. 3. Patient no. 50. The course of weight gain and temperature change following leucotomy. In anorexia nervosa body temperature is usually very low and tends to fall during the passage of each day, rising at night. As weight is restored body temperature rises and a normal rhythm is usually established when the patient's weight approaches the target weight, probably in conjunction with restoration of gonadotrophic function (Crisp, 1970). The daily temperature record shown above reflects the daily mean of 4-hourly oral and rectal temperatures. It is at this point of maximal temperature change that the patient's fear of further weight gain temporarily overrides her impulse to eat and is associated with a staving-off of this process through what proved to be a temporary recurrence of carbohydrate avoidance.

3) and which coincided with the need to mobilize her, thereby exposing her to the hazards of greater freedom, she became acutely panicky and radically reduced her food intake, especially of carbohydrate, for a few days.

Shortly afterwards she surrendered to her now pervasive impulse to overeat and began to stuff herself with food at every opportunity. She became increasingly distressed and angry with the staff and was, only with difficulty, encouraged to stay in hospital.

During the next 4 months she passed through many crises before eventually becoming relatively more settled in her behaviour. She went out to work as a nurse again, becoming involved in the field of therapeutic abortion and abandoning the efforts she and others had previously made to help her become a proficient shorthand typist. Thereafter, she remained for several years a rather solitary person, tending to eat secretly, especially at night, and maintaining a weight of around $64 \mathrm{~kg}$.

After about 2 years her cyclical menstrual bleeding returned for the first time after over 20 years. During this period she refrained from accepting out-patient follow-up appointments but kept in touch through occasional greetings cards. During 1971 she wrote asking for further help, and after interview was accepted for regular out-patient group psychotherapy. Since then she has begun to develop a somewhat more active and mature social life. She now enjoys teasing the medical staff over the difficult time that she gave them post-operatively, and it is evident that she is experiencing an increasingly rich and full existence and enjoys doing so. She remains somewhat overweight at about $59 \mathrm{~kg}$ but her weight is steady and her eating is increasingly normal in its pattern.

\section{Subject No. 201}

This 32-year-old single children's nurse had had anorexia nervosa since the age of 17 . She was first seen in 1970, having been transferred from another psychiatric hospital where she had been an in-patient for the previous 15 months. There was a 15-year history of anorexia nervosa, severe depression and social withdrawal, a life-long history of social phobias becoming increasingly severe since 1967 , and intermittent episodes of depersonalization and panic.

The patient was born by caesarian at 8 months' gestation. Her mother had multiple valvular heart disease and almost died during the delivery. There was no nursing care by the mother during the first month and very little during the first year, the mother being too ill and having simply to prop the baby up with a bottle most of the time. Up to the age of 12 the patient's life was haunted by a great fear of the mother's illness and imminent death. This fear was exacerbated by her alcoholic father's frequent abusive and violent rages, during which she believed he might kill either himself or her mother. She was a quiet, tense, socially withdrawn child who always felt different in some way from her peers and in particular was terrified of ball games. She longed for a sister. She had also had frequent night terrors and sleep walking. During the latter she would always walk to her mother's room, look at her mother and then go back to bed. At the age of 11 she was sent to a special outdoor school for 'nervousness and poor weight'. There was, however, no history of poor eating. Prior to adolescence she was a good student. During adolescence her scholarship diminished, she became withdrawn from her friends and experienced increasing social fears, although she managed to continue to take part in dancing and dramatic classes. At the age of 17 she began training as a nurse and her dieting behaviour first emerged. The latter became much more obvious at the age of 21 when she had a broken engagement and left home, and it was at this time that her social withdrawal and panic 
reactions first came into prominence. At 23 she took a job as a nanny and was happy for the first time in her life. During this period she gained weight and had a return of periods. Shen then impulsively took a job as a model and developed a severe exacerbation of phobias, panic reactions, depersonalization and anorexia nervosa. On her first admission she was diagnosed as having a phobic anxiety depersonalization state, with chronic anorexia nervosa, and was treated for 6 months with a variety of psychotropic drugs, psychotherapy and some refeeding. During her stay on the ward she had several episodes of selfmutilation and gross panic attacks during which she would bash her head against the wall. She found it extremely difficult to eat in the presence of others. She could not accept the weight gain and discharged herself shortly afterwards. Her psychotherapy was marked by her great fears of expression of any aggressive feelings. She experienced extreme tension which was most marked in the early mornings. During the subsequent admission aged 31, refeeding and psychotherapy were again tried without success and she accepted advice to undergo leucotomy.

In April 1972 she had a cryogenic stereotactic limbic leucotomy. Three bilateral lesions were placed in the lower medial quadrant of the frontal lobe (sites 1, 2, 3; Richardson 1973), two bilateral lesions in the anterior cingulum (sites 4, 5; Richardson 1973) and two lesions in each side of the genu of the corpus callosum. These sites were found to be those at which respiration and other physiological parameters were maximally affected. Following leucotomy she gained weight rapidly to her target level and her psychological content "changed dramatically. In the first instance, her early morning tension changed to depression and overt anger. This was most noticeable in relation to meals during which she frequently felt an impulse to throw her meals around the room; she also had several, for her, very disturbing dreams in which she attacked close friends and members of the staff with knives. At this point she associated her visual hallucinations of hands approaching her in the dark (a longstanding symptom regarded by us as a non-psychotic phenomenon), with her father's earlier attacks upon her during childhood. Her recovery has been complicated by the break-up of a long-term very close relationship with a girl friend, and it is not yet possible to asses her future adjustment.

At present, however, she is maintaining her weight, although she still experiences great tension in relation to eating and social contact. There was a mild transitory return of self-destructive behaviour. One promising aspect of her post-leucotomy phase has been a voluntary holiday with her parents. Previously she had experienced unbearable tension in their presence, and had not seen them alone (without staff) for more than a few minutes in 4 years.

\section{Repertory grid material}

The repertory grid is a psychological test which, when analysed by Principal Component Analysis (Slater, 1965), provides a technique for examining the importance to the self of attributes such as weight (expressed here as 'me at minimal weight ever', 'me at maximum weight ever', 'me at matched population mean weight', 'me at sub-menstrual weights, or ideal weights') and of differences in the way one sees oneself, or the way one would like to be (in our data shown as 'me now' or 'me as I would like to be') over periods of time where changes might logically be expected, for example before and after leucotomy. Concepts such as 'me now' etc. are traditionally called elements.

Two features of this analysis are that the importance and meaning' of elements can be given quantitative values and represented graphically. The latter is shown as straight lines, each of which represents a principal component. The principal component can be considered as a statistical 'best fit' for the variables tested and bears similarity to the findings of a cluster analysis, or a factor analysis in bringing together related areas. The principal components are bipolar, their positive and negative ends being determined by the values of the patients' ideas. The quantitative value is derived from two sources. Firstly, the stronger the component (expressed as a percentage of the total positive variance of a patient's ways of using ideas and people in the test), the greater the relative value of the loading score. Secondly, the loading score on the component is an absolute statement of the personal importance of that element.

The grids were elicited at different times postoperatively. Case 103 was done shortly after operation and thus reflects a degree of disarray of psychological organization which invariably accompanies profound change. The others were done between 10 months and 6 years post-operatively and are established positions.

Case 103 demonstrates one pattern of anorexic conceptual organization with regard to weight (the repertory grid data in relation to this case are described in detail elsewhere (Crisp \& Fransella, 1972). As can be seen (Fig. 4), the first component is very powerful $(63 \%)$ especially as it accounts for 6 times the variance of the second component. In psychological terms this would appear to mean that the psychological world of the patient is very rigid, unidimensional and therefore inflexible, and in this case very much determined by weight (as evidenced by the highly rated positions of the patient given by herself at different weights). The point we wish to make is that the ideal weight, in this case $7 \frac{1}{2}$ stone, is separated from 8 stone (the target weight) and 4 stone $10 \mathrm{lb}$, her admission weight, by 24 units. It should be noted that $7 \frac{1}{2}$ stone is a premenstrual 


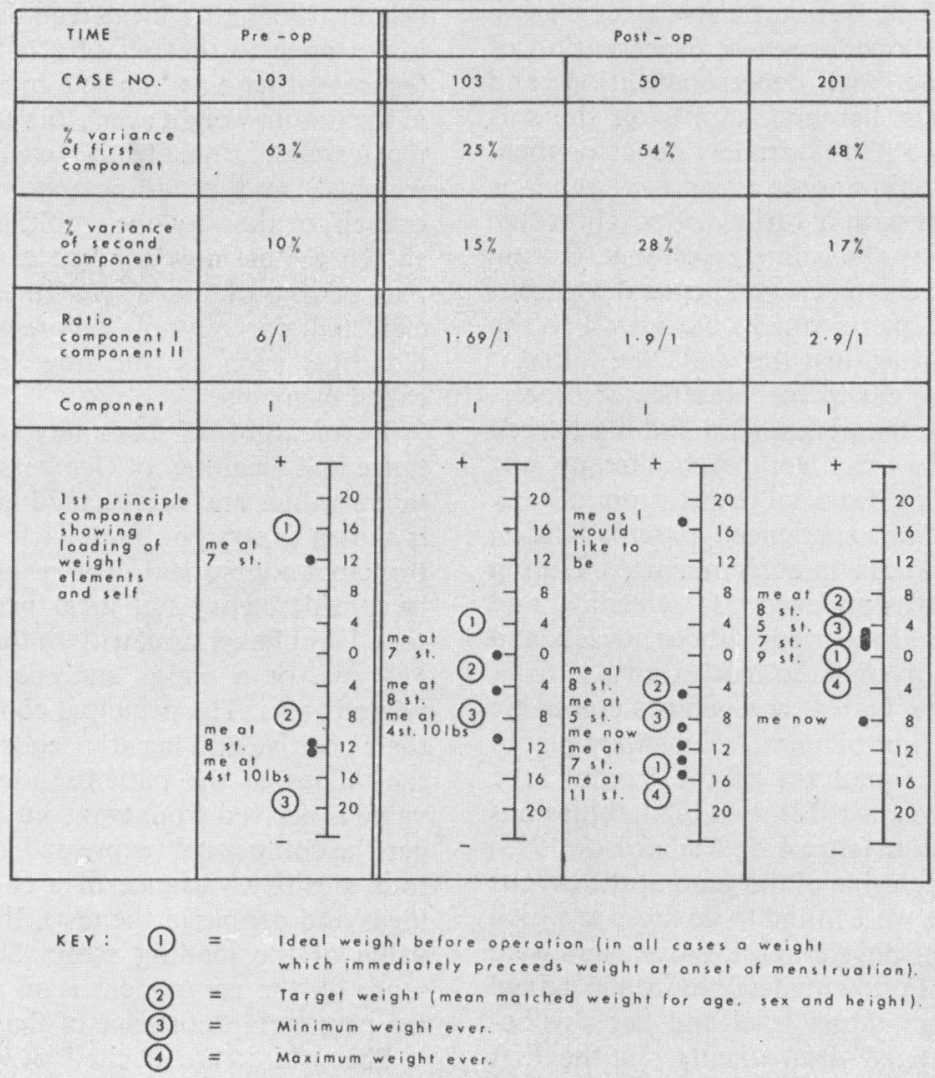

FIG. 4. Some details of pre- and post-operative conceptual organization in three patients with particular reference to self weight concepts.

weight in her case, and that 8 stone is seen as being over weight and a weight at which she would have problems, and 4 stone $10 \mathrm{lb}$ her weight at which she was physically ill and faced with difficulties of hospitalization. The second grid on the same patient shows a dramatic change post-operatively. Firstly, the first component is very much smaller $(25 \%)$ and only 1.69 times as potent as the second component, that is her psychological world has strong alternative dimensions within it for organizing her ideas and psychologically important people in her life. Again, weight is loaded on the first component but in this case the difference between $7 \frac{1}{2}$ stone, 8 stone and 4 stone $10 \mathrm{lb}$ is only 8 units, and all are seen as being relatively negative in an evaluation. The negative evaluation given to these weights is that she saw herself as being irritable, hurtful and aggressive. The meaning of the close accumulation of these weights becomes more apparent in the first component of case 50, who was tested post-operatively, and where the weights again accumulate on the negative end of a rather powerful construct, but with the concept 'me now', that is the way the patient currently sees herself, placed in the middle of the group. There is little differentiation between herself at different weights and in general she sees herself as being much the same at any weight, coincidentally rather negatively, and well away from how she would like to be, which is placed high up on the positive end of the first component. The meaning of this construct was that at the positive end she could see herself as accepting others as active, healthy and kind, whilst at the negative end she saw herself as the opposite of these properties and in addition self-conscious. It 


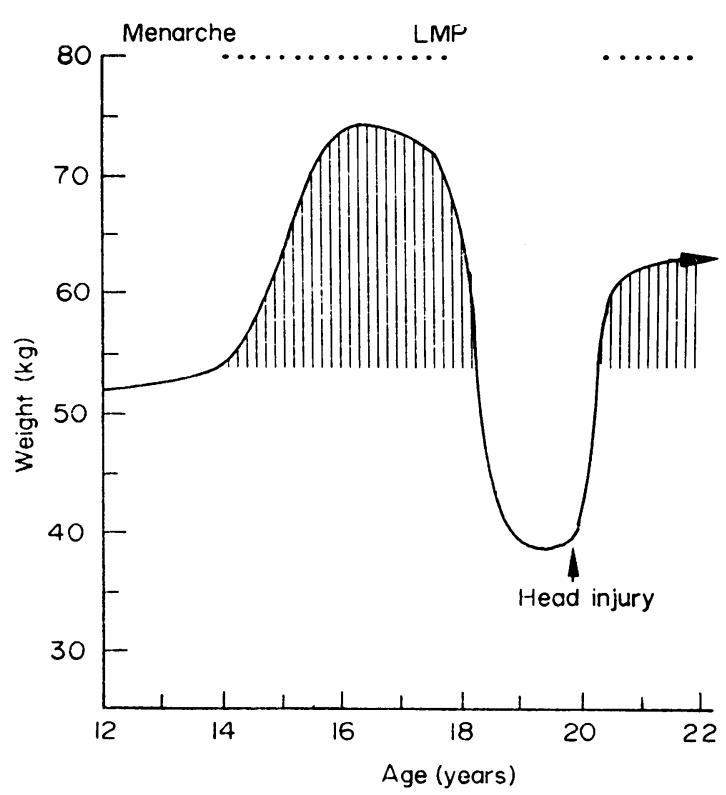

FIg. 5. Weight change following a severe head injury in a patient who had anorexia nervosa (Case 222). The weight change was based on the 'release' of eating behaviour.

can be seen that in the post-leucotomy component previously discussed, Subject no. 103 again did not differentiate between various aspects of herself to any great extent on various weights. In Subject no. 201 the first component post-operatively is again a very strong one, although as with Subject no. 50 not grossly out of proportion to the second component, being only 2.9 times as strong. In this case, the patient groups all weight elements together over a very narrow area around the zero point, whilst she sees 'herself as she is now' as being negatively loaded. A zero loading reflects relative insignificance. One interesting component of this grid was that she saw herself 'as she would like to be' (not shown) in the group of weight-related elements. This component is not highly evaluative, although it is a strong component and perhaps, at least in the clinical context, reflects the great difficulty she is having in adjusting to the increased access that she experiences to her aggressive and destructive feelings, and the associated depression that accompanies them. Before the leucotomy she may not have been happy but she was not aware of the kind of difficulties she had, and in a small way would like to return to that position, feeling that her current situation is very difficult to cope with. The patient has for the first time in two years been able to live out of hospital and is currently nursing her ill mother effectively.

\section{Discussion}

In the few cases described in the literature it is clear that leucotomy has been recommended only if all else has failed, and the time has come when it is evident to all that the patient is likely to die in the near future with or without frequent resuscitation. Under the circumstances the fact that several patients are reported as having subsequently become physically robust has to be measured against the evidence that in some such cases an abnormal feeding pattern has been established, whilst in one or two other instances death has subsequently occurred by suicide. Approximately half the deaths that occur in clinical populations of patients with anorexia nervosa are through suicide (Crisp, 1969).

One patient, no. 51, was clearly unable to tolerate the consequences of leucotomy. Its effects on her appeared to be that of altering the balance of her bulimia/vomiting pattern, with which she had previously achieved the weight control necessary for her for so many years, in such a way that she started to gain weight. Whether this was a direct effect upon cerebral centres governing nutritional processes or whether it was some other effect is not clear. Perhaps, for instance, in the immediate post-operative period she expected the operation would allow her to gain weight without the same fear as before. However, within a few weeks it was clear to her and to us that her terror in this respect was unabated. Although she looked so much better physically she clearly now found herself intolerable. We did not know what her feeding patterns were after she discharged herself, but we do know that she killed herself within 3 weeks.

Faced with this solitary experience, the first author was nevertheless confronted with the logic of having to advise leucotomy again in the next case, no. 50. But it is fair to say that this patient has done remarkably well whilst without the operation she would probably now be dead. While she is comparable with the first case in terms of the chronicity of her illness, she is very different in other responses. Whereas the first patient's problems of impulse control were widespread and overt in other respects, especially in the sexual sphere, and also repugnant and terrifying to her, the second patient had always led a sedate, restricted existence with a well-defined social adjustment as a nurse and dutiful daughter, her only appetitive indulgence on a behavioural level having been to overeat as a child. Post-operatively it was bulimia and food stealing which characterized her early convalescent phase. It proved possible within the context of in-patient care to provide her with some skill in the control of this behaviour. From this basis, and with increasing awareness of thestarkly unrewarding nature of her life and personal limitations, she had gradually expanded her social contacts. The leucotomy appears to have weakened parts of her defence system, allowed objective 
assessment, and reduced the otherwise unbearable tension to an extent that some flowering of her potential is possible.

Patient no. 103, who has done exceedingly well, was without doubt the most 'stable introvert' amongst the four patients, and like patient no. 50 her illness had started relatively early. Although we were particularly reluctant to advise such a young patient to undergo leucotomy it may be that her relative youth and shorter duration of illness were an advantage to her in that, post-operatively, she did not find such a time gulf requiring to be bridged between herself and her peers. This latter factor is a crucial one for all patients with anorexia nervosa, affecting their potential for recovery whatever treatment programme is undertaken.

Patient no. 201 is in many ways intermediate between cases no. 50 and 103 . She has a chronic history and has therefore been separated from normal maturational experiences for many years. Like case 103 she was a stable introvert as a child and young adolescent, but in her late adolescence and even in her early twenties, when she went through a phase of overeating and vomiting within her anorexia nervosa, she had begun to behave impulsively both in respect of her social life and in terms of some selfmutilating behaviour. After leucotomy there has been a real release and differentiation of her feelingstension became depression and anger - and of her fantasies and dreams illustrating her destructive wishes towards loved ones. She remains in hospital and is disconsolate and hesitant to explore life, but plans to return to live with her parents.

The mechanisms whereby the leucotomy procedures effected the changes described above are obscure. In three instances the lesions were placed in the lower medial quadrant of each lobe, in the other instance they were placed in the sites described above. In very general terms such lesions might be expected to relieve aversive states (tension and depression) and perhaps to tilt behaviour in the direction of 'pleasurable experiences and behaviour'. Within such an effect it might be expected that release of appetitive behaviour would go hand in hand with diminution of anxiety and tension. However, the phobia of normal weight which characterizes anorexia nervosa and which owes a great deal to symbolic processes was certainly not correspondingly reduced in the first of our cases. These cortical processes became more apparent in cases 50 , 201 and 103, and although in the first two cases they were a cause of great distress, they were certainly available to modification through psychotherapy.

The point that the release of eating behaviour is not necessarily accompanied by a corresponding relief of tension, is emphasized in the following brief case report. This patient is a 22-year-old girl who had developed anorexia nervosa at the age of 17 in relation to feelings of loneliness and of being unattractive to men, which she felt was due to her obesity. Three other events which appear to be important to the onset of her dieting behaviour, and consequent intense adolescent weight phobia, were the marriage of her brother to a girl who was extremely thin, moving away to a new area (increasing her loneliness), and starting work for the first time. Her premorbid childhood adjustment was marked by considerable recklessness and tomboyish behaviour (of an impulsive kind), whilst her adolescent behaviour was of extreme compliance, even-temperedness and minimal heterosexual interest, and a very close and sisterly relationship with her mother. At the age of 19 she fell off her bicycle while riding to work. Overactivity was a marked aspect of her syndrome and it is suspected that her accident was related to an epileptic fit. (Symptomatic epilepsy occurs in about $10 \%$ of patients with anorexia nervosa and is related to such factors as water loading and electrolyte depletion.) She had a severe head injury with complete right-sided paralysis and a marked speech defect. Both still become evident when she is tired. She was unconscious for $\mathbf{8}$ days, and on recovering developed a voracious appetite with frequent stealing of food and episodic depression. Since regaining her weight she has fluctuated between bulimia and abstinence. There have been chaotic behaviour and feelings in relation to these periods; feelings of disgust, fury and depression, intermittent overdoses of drugs, erratic changes of jobs, and very unstable personal relationships with her parents and fiancé have emerged. Sexual fantasies have been much more in evidence. It appears that the head injury released both eating behaviour, consequent rapid weight gain, and an increasing awareness of her sexual life, but in no sense contributed to a capacity to control her behaviour or to reduce her fear and shame in relation to increasing weight (Fig. 5).

In our view it is also important to take into account the meaning of the operation, or for that matter the meaning of brain damage from accidental or selfinflicted injury, to the individual who has undergone it. He or she may conceive of the operation or resultant and induced brain damage as absolving them from responsibility for subsequent behaviour. Fear, guilt and other inhibiting influences may thereby be discarded. Such 'licence to change' could be one of several expectancy factors operating in the patient and those around her which might contribute to the effect of leucotomy.

Whatever the mechanism, we believe that change occurs in patients with anorexia nervosa following leucotomy, and that this often leaves them with new opportunity and potential for adaptation and redevelopment. In the first instance all such patients 
will be much more vulnerable than before. In the majority of instances, of course, patients with anorexia nervosa either recover spontaneously, or can be helped to get better by the kind of extended treatment programme described elsewhere without any intervention such as leucotomy. The change that does occur after leucotomy is in general of a kind which is in every sense recognizable as part of the natural history of anorexia nervosa as described above. The patient's threshold for controlling eating is exceeded and she may now enter into other maladaptive behaviour, bulimia, secret eating, etc., associated with fear and despair. There is a potential here for creating another pattern of chronic vomiting and purging to control weight, for suicide, or for aiding the patient to a new adjustment to adult weight. We have indicated that part of this aid requires a pre-operative commitment by the patient to accept the dangerous refeeding period in hospital where the resources of the institute can be brought to bear on a patient who is increasingly open to change. It appears from these cases that the following factors contribute to outcome and may help to show where leucotomy is contra-indicated. These include the patient's premorbid behaviour (which often means childhood and very early adolescence), the quality of her impulse control, the chronicity of her illness, and the extent to which chronic illness has excluded any form of adjustment. In our view the patient who, after such considerations, may be advised to undergo leucotomy, needs to appreciate the crucial importance of the post-operative period which will involve her in intensive psychotherapy and rehabilitation over a period of months or years, including in the first instance extended in-patient care. The task confronting the patient is the same as that for any patient with anorexia nervosa whose weight is fairly rapidly restored to normal levels, namely that of 'growing up' in every sense, this being the developmental and maturational demand of the imposed weight change.

It is our view therefore that, within the range of therapy for primary anorexia nervosa, leucotomy procedures have and will continue to have a limited but very definite place.

\section{Acknowledgments}

We wish to acknowledge the help of many people in the treatment of these patients, especially the nursing staff and the neurosurgeons, Mr Valentine Logue and his colleagues at the Middlesex Hospital, and Mr Alan Richardson at St George's Hospital. We also wish to record our admiration for our patients who struggle to free themselves from their stifling illness.

\section{References}

Altschule, M.D. (1953) Adrenocortical function in anorexia nervosa before and after lobotomy. New England Journal of Medicine, 248, 808.

Carmody, J.T.B. \& Vibbler, F.L. (1952) Anorexia nervosa treated by lobotomy. Annals of Internal Medicine, 36, 647.

CrisP, A.H. (1967a) Anorexia nervosa. Hospital Medicine, May, 713.

CRISP, A.H. (1967b) The possible significance of some behavioural correlates of weight and carbohydrate intake. Journal of Psychosomatic Research, 11, 117.

CRISP, A.H. (1969) Leading article: Anorexia nervosa. British Medical Journal, 1, 529.

Crisp, A.H. (1970) Anorexia nervosa; 'feeding disorder', 'nervous malnutrition' or 'weight phobia'? World Review of Nutrition and Dietetics, 12, 452.

Crisp, A.H., Chen, C., Mackinnon, P.C.B. \& Corker, C. (1973) Observations of gonadotrophic and ovarian hormone activity during recovery from anorexia nervosa. Postgraduate Medical Journal, 49, 584.

Crisp, A.H. \& Fransella, F. (1972) Conceptual changes during recovery from anorexia nervosa. British Journal of Medical Psychology, 45, 395.

Dally, P. (1969) Anorexia Nervosa, p. 63. Pitman Press, Bath.

DRURY, M. O'C. (1950) An emergency leucotomy. British Medical Journal 2, 609.

Glazebrook, A.J., Mata, J. \& Prosen, H. (1956) Compulsive neurosis with cachexia. Canadian Medical Association Journal, 75, 40.

Hemphill, R.E. (1944) Return of virility after prefrontal leucotomy. Lancet, ii, 345.

Kelly, D. \& Mitchell-Heggs, N. (1973) Stereotactic limbic leucotomy: a follow-up study of thirty patients. Postgraduate Medical Journal, 49, 865.

Mallinson, P. (1953) Discussion of anorexia nervosa. Proceedings of the Royal Society of Medicine, 46, 669.

Richardson, A. (1973) Stereotactic limbic leucotomy: surgical aspects. Postgraduate Medical Journal 49, 860.

SARGANT, W. (1951) Leucotomy in psychosomatic disorders. Lancet, ii, 87.

SifNeos, P.E. (1952) A case of anorexia nervosa successfully treated by leucotomy. American Journal of Psychiatry, $109,356$.

Slater, P. (1965) The Principle Components of a Repertory Grid. Vincent Andrews, London.

Slater, P. (1965) The use of the repertory grid technique in the individual case. British Journal of Psychiatry, 111, 965. 